\title{
Non-invasive sampling reveals fine-scale genetic structure in black bear Ursus americanus populations from northeastern Mexico
}

\author{
Fernando Montiel-Reyes ${ }^{1}$, Jesús E. Maldonado ${ }^{2,3}$, Melina Del Real-Monroy ${ }^{1}$, \\ Norberto Martínez-Méndez ${ }^{4}$, Jorge Ortega ${ }^{1, *}$
}

\footnotetext{
${ }^{1}$ Laboratorio de Bioconservación y Manejo, Posgrado en Ciencias Quimicobiológicas, Departamento de Zoología, Escuela Nacional de Ciencias Biológicas, Instituto Politécnico Nacional, Prolongación de Carpio y Plan de Ayala s/n, Col. Sto. Tomas, 11340, México, DF

${ }^{2}$ Center for Conservation and Evolutionary Genetics, Smithsonian Conservation Biology Institute, 3001 Connecticut Avenue NW, Washington, DC 20008, USA

${ }^{3}$ Department of Vertebrate Zoology, National Museum of Natural History, Smithsonian Institution, MRC 108, Washington, DC 20013, USA

${ }^{4}$ Laboratorio de Bioconservación y Manejo, Posgrado en Biociencias, Departamento de Zoología, Escuela Nacional de Ciencias Biológicas, Instituto Politécnico Nacional, Prolongación de Carpio y Plan de Ayala s/n, Col.
} Sto. Tomas, 11340, México, DF

\begin{abstract}
The black bear Ursus americanus is one of the largest terrestrial carnivores that has a wide distribution in northeastern Mexico, the only country in which black bears are listed as endangered. We used 10 nuclear microsatellite loci to evaluate black bear genetic variability in 6 disjointed populations from northeastern Mexico. Non-invasive genetic techniques were applied to fecal and hair samples. Using a panel of 10 polymorphic microsatellites we identified 64 individuals. Black bears showed low to moderate levels of genetic diversity in all sampled populations (mean \pm SD expected heterozygosity, $H_{\mathrm{e}}=0.63 \pm 0.628$ ). Pairwise comparisons between all 6 populations $\left(\phi_{\mathrm{ST}}=0.315, \mathrm{p}<0.05\right)$ detected significant genetic differentiation between the western Coahuila and the northeastern Nuevo León regions, suggesting that black bears have low levels of gene flow between these 2 regions. Microsatellites revealed significant structure within the complex of disjoint areas in the region. The inbreeding coefficient was also significant $\left(\phi_{\text {IS }}=\right.$ 0.143). The largest proportion of genetic variation $(82.7 \%)$ was found between individuals within populations. Distance and anthropogenic activities may serve to limit gene exchange among populations which form at least 3 distinct genetic clusters; these may respond differently to environmental changes and should be considered distinct management units.
\end{abstract}

KEY WORDS: Black bears $\cdot$ Genetic structure $\cdot$ Microsatellite $\cdot$ Non-invasive sampling $\cdot$ Mexico

\section{INTRODUCTION}

Factors influencing the genetic structure of species are important for understanding how populations change over time and for predicting how such changes affect evolutionary processes. Several studies on the genetic structure of vertebrates have pro-

${ }^{*}$ Corresponding author: artibeus2@aol.com vided indications of the possible effects of natural and artificial dispersal on subpopulations of a particular species (Friesen et al. 2006, Small et al. 2006, McDevitt et al. 2013). Other studies have shown the importance of habitat fragmentation and heterogeneity and the effects of genetic drift of subpopulations as a consequence of restricted dispersal (Bergl

(C) The authors 2014. Open Access under Creative Commons by Attribution Licence. Use, distribution and reproduction are unrestricted. Authors and original publication must be credited. 
\& Vigilant 2007, Heller et al. 2010). A number of analyses have shown low to medium values of genetic diversity among populations of large mammals resulting from low densities throughout the species' respective ranges and despite the high dispersal rates of some individuals (Lawson Handley \& Perrin 2007, Archie et al. 2008).

Black bears Ursus americanus are present in all Canadian provinces, in almost all of the USA except for the arid areas of the southwest, and also in the Sierra Madre Occidental and Sierra Madre Oriental of Mexico (Larivière 2001). In Mexico, black bears primarily inhabit sparsely populated forest areas above $2000 \mathrm{~m}$ in the northeast and northwest ranges of both Sierras Madre. Mexico is the only country where black bears are listed as endangered (Ceballos et al. 2002) because they have been severely affected by adverse factors such as habitat loss due to anthropomorphic activities, climate change, poaching, and illegal trade (Sierra Corona et al. 2005). Black bear populations inhabiting these high-elevation woodlands are often separated by the more inhospitable desert and grassland habitats in the lowlands (Varas-Nelson 2010). However, as the available habitat on mountain tops has become smaller and more fragmented, black bears are occasionally forced to attempt to move through the desert lowland to reach woodlands in neighboring mountains areas (LeCount \& Yarchin 1990). These lowland areas have also been highly impacted by anthropogenic disturbances and barriers due to industrial and agricultural development, which has affected the ability of individuals to disperse to nearby mountains (Varas-Nelson 2010). The current status of the black bear population in the southeastern highlands of Coahuila and Nuevo León, Mexico, is poorly understood due to the scarcity of records in scientific collections and the lack of reliable data from observations of individual animals. On the other hand, the black bear populations in western Coahuila appear to be healthy and stable as a result of conservation management in the protected areas and well-preserved suitable habitats (Doan-Crider \& Hellgren 1996).

Here we used non-invasive sampling coupled with molecular neutral markers to assess the genetic diversity and genetic structure of black bear populations in northeastern Mexico. Our particular objectives were to assess the levels of genetic diversity of black bear populations and compare our results with nearby populations in the southeastern USA. We tested the hypothesis that black bear populations from western Coahuila have lower levels of genetic differentiation and higher levels of gene flow with populations of western Texas (USA) than with populations from the southeastern highlands of Coahuila and Nuevo León. We predicted that black bears from western Coahuila are more likely to disperse long distances along high-elevation woodland habitats in the same mountain range than to cross shorter geographic distances through inhospitable desert habitat between the eastern and western Coahuila highlands. We also evaluated the levels of genetic diversity and subdivision between highly impacted populations in the western highlands of Coahuila and Nuevo León compared to the less impacted populations of northeastern Coahuila.

\section{MATERIALS AND METHODS}

\section{Study area}

We sampled an area that encompassed most of the known current distributional range of the black bear Ursus americanus in northeastern Mexico (Fig. 1). The 6 sampling sites were located in the southeastern highlands of the states of Coahuila and Nuevo León, and also in the northeastern part of Coahuila (Sierra del Burro and Sierra del Carmen). Overall, the habitat in the desert areas is characterized by abundant xero-

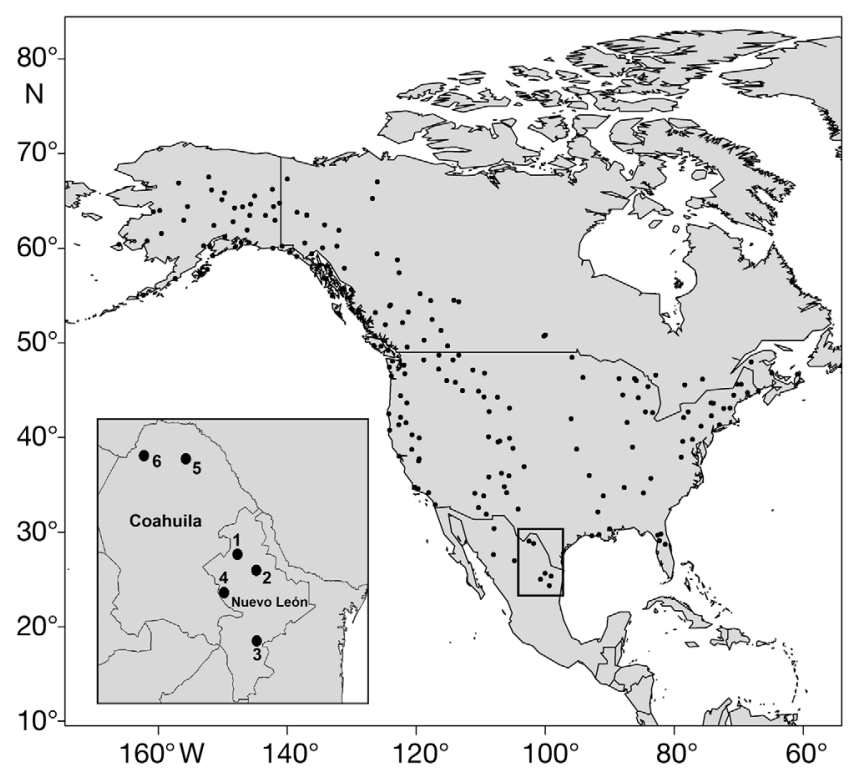

Fig. 1. Historical distribution of Ursus americanus in North America. Inset shows sampled sites in northeastern Mexico for black bear populations in the states of Coahuila and Nuevo León: 1, Real de Minas Viejas/Villaldama; 2, Sierra de Picachos; 3, Linares; 4, Santa Catarina; 5, Sierra del Burro; 6, Sierra del Carmen 
phytic vegetation and rocky outcrops in the arid regions, while in the mountains, 6 different associations of pine and oak woods are recognized (JiménezGuzmán \& Zúñiga-Ramos 1991). The highland areas are mainly comprised of oaks Quercus hypoleucoides and Q. muhlenbergii, pines Pinus strobiformis and $P$. arizonica, and cedar Juniperus deppeana and are characterized by steep peaks with deep canyons, with an average elevational gradient of $1750 \mathrm{~m}$. The arid land ranges in altitude from 1000 to $1500 \mathrm{~m}$, and has the floristic characteristics of the Chihuahuan Desert, i.e. it mainly supports Larrea tridentata, Agave lechuguilla, and Parthenium incanum (Muldavin 2002). These areas are considered unsuitable habitat for black bear populations (Onorato et al. 2007).

The northeastern part of Coahuila consists principally of an elevated limestone plateau that is an extension of the northern Chisos Mountains in Big Bend National Park of Texas. The 2 mountain areas are part of the same system of uplifts, but they are separated by the Rio Grande valley and are composed of different types of rock (Miller 1955). Both sampling sites are located in the Chihuahuan Desert and are within the protected areas of the Maderas del Carmen Biosphere Reserve, which include several private properties and communal agricultural lands ('ejidos'). Even though this is a protected area with suitable habitat and with abundant food resources for black bears, the illegal extraction of stony material and xeric/timber products, hunting, and grazing continue to pose problems (Onorato et al. 2007).

The southeastern part of Coahuila and Nuevo León is located in the northeastern mountain range of the Sierra Madre Oriental. Our sampling sites were located at some of the highest points in the mountain ranges (Picachos and Santa Catarina), where pine-oak is the predominant vegetation. Land use around these sites includes livestock production, wildlife-based recreation, grazing areas, and heavily populated/industrial zones (i.e. the urban areas of Monterrey and Saltillo).

\section{Sample collection}

Because direct sighting of, and sampling from, wild black bears is very difficult, we used non-invasive fecal and hair sampling as a source of DNA. Our sampling was designed to obtain fecal and hair samples from as many different individuals as possible in the area in an effort to maximize complete sampling of the populations in the different areas so as to assess levels of genetic diversity and structure. Between 2008 and 2012, we surveyed transects throughout the 6 different locations, walking a maximum distance of $10 \mathrm{~km}$, searching for fecal material and placing 10 baited barbed wire hair traps at intervals of $1 \mathrm{~km}$ (Woods et al. 1999). Transects were surveyed during dry field seasons (February to May) in the early morning to avoid negative effects of the weather on the feces (Hájková et al. 2006). In the dry season of each of the 5 years of the study period we checked for scats and set hair snags. Fresh fecal samples were placed in Falcon tubes with silica gel and transported to the laboratory for analysis. Black bears are the only large carnivore present in the area and therefore we did not need to identify fecal samples to species using a genetic marker because visual identification and size of feces were conclusive for species identification. We collected hair samples mainly from wire hair traps, but we also looked for evidence of hair on fences with evident signs of scratching posts. We used hair traps only once in each site during the 5 yr period because of the higher cost and time effort required to maintain and sample them. We assumed that every clump of hair collected in each wire trap belonged to a single individual because traps were carefully monitored and checked daily during the sampling period.

\section{Laboratory procedure}

Whole genomic DNA was extracted from fecal samples using the QIAamp DNA Stool Mini Kit and from tissue using the DNeasy Tissue and Blood Kit (Qiagen) in a separate room from PCR products (Eggert et al. 2005). For each hair trap, 5 to 10 hairs with evident roots were incubated overnight with Proteinase K. We extracted hair DNA by applying the universal salt-extraction protocol (Aljanabi \& Martínez 1997). We optimized DNA amplification following the standard protocol suggested by Lampa et al. (2008). Quality of DNA was assessed by electrophoresis on $1 \%$ agarose gels in combination with molecular weight standards.

Ten nuclear microsatellite loci specifically designed for $U$. americanus (UamA2, UamA107, UamB8, UamB103, UamB125, UamD11, UamD102, UamD103, UamD113, UamD116, Meredith et al. 2009), were amplified via PCR in a $20 \mu \mathrm{l}$ reaction volume using approximately $10 \mathrm{ng} \mathrm{ul}^{-1}$ of target DNA (fecal/hair), 1× buffer, $0.4 \mathrm{mM}$ dNTPs, $0.8 \mu \mathrm{M}$ forward primer labeled with FAM fluorescence (Invitrogen), $0.8 \mu \mathrm{M}$ reverse primer (Invitrogen), 2 to $3.75 \mathrm{mM} \mathrm{MgCl}_{2}$, and 
$2 \mathrm{U} \mathrm{\mu l}^{-1}$ of Taq DNA polymerase (Promega). We used an Applied Biosystems 2720 Thermal Cycler under the following conditions: $94^{\circ} \mathrm{C}$ for $180 \mathrm{~s}$, followed by 35 cycles at $94^{\circ} \mathrm{C}$ for $60 \mathrm{~s}$, annealing temperature (as reported by Meredith et al. 2009 for each primer) for $30 \mathrm{~s}$, and $72^{\circ} \mathrm{C}$ for $30 \mathrm{~s}$; followed by $240 \mathrm{~s}$ at $72^{\circ} \mathrm{C}$ and a final step of $4^{\circ} \mathrm{C}$. PCR products were confirmed by electrophoresis in $1.5 \%$ agarose gels stained with ethidium bromide using a $100 \mathrm{bp}$ ladder and a negative control. The products were dried (SpeedVac REC10.10.-RCT0; Jouan) and genotyped on an ABI Prism 3100 sequencer (Applied Biosystems).

We carried out all of the pre-PCR procedures in sterile conditions in a separate room using aerosol barrier tips to minimize cross-contamination. Negative controls were included in all extractions and PCR to detect the presence of any exogenous DNA or reagent contamination. To account for error rates such as false alleles (FAs) and allelic dropout (ADO), we followed a modified multi-tube approach of Taberlet et al. (1996) and repeated each PCR 3 times for microsatellite analysis. In order to obtain a final score, we used the most parsimonious score based on the consensus of the 3 scores. We scored homozygotes only when the same allele was detected 3 times and heterozygotes when the same 2 alleles were detected in 2 runs, even if the third run only detected 1 of the 2 alleles. We only included samples that had genotypes that amplified 3 times for all 10 loci.

\section{Data analyses}

The number of alleles (NA), expected heterozygosity $\left(H_{\mathrm{e}}\right)$, and observed heterozygosity $\left(H_{\mathrm{o}}\right)$ per locus per population was estimated according to Nei (1987), as implemented in the programs GENEPOP v. 4.0 (Raymond \& Rousset 1995) and ARLEQUIN v. 3.0 (Excoffier et al. 1992). We estimated allelic richness and private allele richness with correction for sample size through rarefaction using the software HP-RARE (Kalinowski 2005). We performed an exact test for Hardy-Weinberg equilibrium (HWE) per locus using a Markov Chain Monte Carlo (MCMC) procedure with 10000 dememorization steps, and estimated deviations from HWE for each population through the inbreeding coefficient $F_{\text {IS }}$ (Weir \& Cockerham 1984), as well as linkage disequilibrium using the program GENEPOP v. 4.0 (Raymond \& Rousset 1995), with Bonferroni correction (Rice 1989) applied for multiple comparisons. HWE states that allele and genotype frequencies will remain constant among generations in the absence of evolutionary forces.
Because HWE predicts equilibrium genotype proportions, $F_{\text {IS }}$ accounts for the deviation from this equilibrium in terms of inbreeding influence. We used MICROCHECKER v. 2.2.3 (Brookfield 1996, Van Oosterhout et al. 2004) to detect loci containing errors due to scoring or stuttering. We calculated the cumulative $P_{\mathrm{ID}}$ (probability of identity) and $P_{\mathrm{ID}-\text { sibs }}$ (identity for sibling or probability of identity among siblings) value (Waits et al. 2001) using GEMINI (Valière et al. 2002). Cumulative $P_{\mathrm{ID}}$ values provide a measure of the power of our panel of selected markers to distinguish individuals.

Pairwise $R_{\mathrm{ST}}$ (Holsinger \& Weir 2009) was estimated using ARLEQUIN v. 3.0 (Excoffier et al. 2005) with the default values provided by the program and 100 iterations to obtain significance values. The $R_{\mathrm{ST}}$ model was used for our microsatellite data because its mathematical procedure assumes the stepwise mutation process that is a better parameter in microsatellite loci differentiation (Hardy et al. 2003). Isolation by distance was tested through a Mantel test using 2000 permutations with the program FSTAT v. 2.9.3 (Goudet 2001), using the multiple regressions and the linear geographic distances between populations.

We used analysis of molecular variance (AMOVA) in ARLEQUIN v. 3.0 (Excoffier et al. 2005), with 1000 repetitions and confidence intervals based on 20000 repetitions to assess the proportion of variation found between individuals within populations, followed by intra-population variation. The software STRUCTURE v. 2.2 (Pritchard et al. 2000) was used to assess genetic structure. STRUCTURE employs a modelbased Bayesian analysis to cluster groups, performed as an assignment test. Previous runs were analyzed in order to determine the number of burn-in chains and MCMC that maximize the result's posterior likelihood. To determine the optimal number of clusters $(K)$ we used the $\Delta K$ test proposed by Evanno et al. (2005) which is based on the log likelihood obtained for each $K$. We used the program BAPS v. 3.1 (Corander et al. 2003) to estimate the posterior probabilities for the number of populations, the proportion of individuals among the inferred populations, and the relative frequency of alleles.

To see if we could detect signatures of a population bottleneck, we used the program BOTTLENECK (Piry et al. 1999), which tests for heterozygote excess as compared with that expected under mutationdrift equilibrium. First, we used a qualitative approach in the form of an allele frequency distribution test. If any deviation is observed from the normal L-shaped allele frequency distribution, a bottleneck 
may be suspected. We then used a quantitative approach based on the principle that the allelic diversity in a population decreases faster than heterozygosity after passing through a bottleneck, resulting in a relative excess of heterozygotes (Cornuet \& Luikart 1996). The significance of observed deviations was determined by a 2-tailed Wilcoxon signed-rank test (Luikart \& Cornuet 1998), under the 2-phase mutation (TPM) model, with $30 \%$ of mutations explained by the step-wise mutation model (SMM) because it has been suggested to be the most suitable for microsatellites (Luikart \& Cornuet 1998).

\section{RESULTS}

We collected a total of 79 fecal samples from all of our sampling sites (Fig. 1): Real de Minas Viejas/Villaldama $(n=4)$, Picachos $(n=29)$, Linares $(n=6)$, Santa Catarina $(\mathrm{n}=4)$, Sierra del Burro $(\mathrm{n}=15)$, and Sierra del Carmen $(n=21)$. We also collected 47 hair samples from 3 different sites: Santa Catarina $(\mathrm{n}=21$ from 5 different traps), Sierra del Burro ( $\mathrm{n}=12$ from 4 different traps), and Real de Minas Viejas/Villaldama ( $\mathrm{n}=14$ from 4 different traps). In total, we collected 126 samples and were able to identify 64 individuals with a cumulative $P_{\mathrm{ID}}$ of $(1.6-2.3) \times 10^{-6}$ and $P_{\mathrm{ID}(\text { sibs }}$ of $(3.9-5.2) \times 10^{-3}$. The total number of identified individuals per site was: Real de Minas Viejas/Villaldama $(n=8)$, Picachos $(n=17)$, Linares $(n=4)$, Santa Catarina $(n=9)$, Sierra del Burro $(n=13)$, and Sierra del Carmen $(n=13)$. Estimates of genotyping errors from multiple replicates of black bear fecal and hair samples resulted in the detection of only 3 cases of ADO, one at Real de Minas Viejas/Villaldama (locus UamA107), and 2 at Sierra del Burro (locus UamB103 and locus UamD113; Table 1), and a low index of FAs in Picacho (0.02). In addition, we discarded samples that had incomplete genotypes in order to avoid problems associated with missing data, so the 64 individuals were identified only using samples that had complete genotypes. In the cases where we had multiple samples with the same genotype (i.e. some hair samples were recaptures of the same individual), only the consensus genotype was used for the genetic analysis. We found a total of 31 alleles for the 10 nuclear microsatellite loci when the 64 individual bear samples identified in this study from all of the sites were pooled. All loci were polymorphic, ranging from 2 to 3 alleles per locus for all populations. Exact tests revealed that 5 of the 7 populations were in HWE ( $p>0.05$ ) after Bonferroni correction for multiple comparisons, but 2 populations (Real de Minas/ Villaldama and Santa Catarina) showed deviation from HWE due to heterozygote deficiency (Table 1). None of the significant tests clustered around a specific locus. None of the tests for linkage disequilibrium was significant at the 0.05 level with a sequential Bonferroni correction. MICROCHECKER software did not detect the presence of null alleles. We estimated the probability of a random match between unrelated individuals for all multi-locus genotypes $\left(P_{\mathrm{ID}}\right.$ unbiased $\left.=[2.2-3.0] \times 10^{-6}\right)$, and for the random match between siblings for all multi-locus genotypes $\left(P_{\mathrm{ID}-\text { sibs }}=[3.5-4.1] \times 10^{-4}\right)$. Both parameters were low, suggesting that our selected panel of microsatellite loci had adequate power to differentiate between individuals.

Allelic richness estimated through rarefaction resulted in 1.8 to 2.2 mean alleles per population, with a mean \pm SD genetic diversity of $0.095 \pm 0.004$ (Table 1). The population from Sierra del Burro had

Table 1. Genetic diversity of 6 populations of black bears Ursus americanus from northeastern Mexico. Microsatellite nuclear markers: A: allelic richness with rarefaction; PA: private alleles with rarefaction; $H_{\mathrm{e}}$ : expected heterozygosity; $H_{0}$ : observed heterozygosity; N: sample size; $F_{\text {IS }}$ inbreeding coefficient; ADO: allelic dropout; FA: false alleles; NA: total number of alleles

\begin{tabular}{|c|c|c|c|c|c|c|c|c|c|}
\hline Population & $A \pm \mathrm{SD}$ & PA & $H_{\mathrm{o}}$ & $H_{\mathrm{e}}$ & $\mathrm{N}$ & $F_{\mathrm{IS}}$ & $\mathrm{ADO}$ & FA & NA \\
\hline $\begin{array}{l}\text { Real de Minas Viejas/ } \\
\text { Villaldama }\end{array}$ & $0.09 \pm 0.002$ & 0 & 0.45 & 0.50 & 8 & $0.346^{\mathrm{a}}$ & $0.073^{b}$ & 0 & 5.0 \\
\hline Santa Catarina & $0.06 \pm 0.003$ & 0 & 0.35 & 0.39 & 9 & $0.212^{\mathrm{a}}$ & 0.0 & 0 & 4.0 \\
\hline Picachos & $0.07 \pm 0.006$ & 0 & 0.65 & 0.66 & 17 & 0.117 & 0.0 & 0.02 & 5.0 \\
\hline Linares & $0.08 \pm 0.004$ & 0 & 0.78 & 0.80 & 4 & 0.156 & 0.0 & 0 & 4.0 \\
\hline Sierra del Burro & $0.15 \pm 0.003$ & 0.04 & 0.62 & 0.64 & 13 & 0.163 & $0.029^{c}$ & 0 & 7.0 \\
\hline Sierra del Carmen & $0.12 \pm 0.007$ & 0.03 & 0.78 & 0.78 & 13 & 0.172 & 0.0 & 0 & 6.0 \\
\hline
\end{tabular}


the highest number of alleles (7.0) and the highest genetic diversity $(A=0.15 \pm 0.003)$, followed by Sierra del Carmen $(A=0.12 \pm 0.007)$ and Real de Minas Viejas/Villaldama $(A=0.09 \pm 0.002)$. The Santa Catarina population had the lowest allelic richness $(A=0.06 \pm 0.003)$. Rarefaction analysis estimated low frequencies of private alleles in Sierra del Carmen (0.03) and Sierra del Burro (0.04).

Population pairwise $R_{\mathrm{ST}}$ values exhibited low to high levels of genetic differentiation (0.02 to 0.4; Table 2). Sierra del Carmen and Linares showed significant levels of genetic differentiation (0.41), and Sierra del Burro and Sierra del Carmen showed the lowest level of differentiation (0.02). These data suggest that moderate levels of gene flow have occurred among some of the populations (e.g. Sierra del Burro/Sierra del Carmen). However, Sierra del Carmen and Sierra del Burro were also the populations that showed the highest nuclear genetic differentiation compared to the other populations. Mantel tests in FSTAT did not detect a significant correlation between geographic and genetic distance measures $(r=0.326, p>0.05)$ among the sampled populations.

AMOVA results showed that the highest proportion of variation occurred between individuals within populations (82.7), followed by intra-population variation (12.2; Table 3). Fixation indices support the presence of genetic structure among populations $\left(\phi_{\mathrm{ST}}=\right.$ $0.315, \mathrm{p}<0.05)$, and inbreeding within them $\left(\phi_{\text {IS }}=\right.$ $0.143, \phi_{\text {IT }}=0.318, \mathrm{p}<0.05$; Table 3). A signature of fine-scale population genetic structuring was detected using the Bayesian cluster approach. In the STRUCTURE analysis, the probability of the data, $\operatorname{Pr}(\mathrm{X} \mid \mathrm{K})$ was highest for $K=3$, suggesting that the sampled black bear sites most likely represent 3 defined genetic clusters. This test assigned individuals from Sierra del Burro/Sierra del Carmen to 1 well differentiated cluster; Picacho, Linares, and Santa Catarina to a second more admixed cluster; and Vil-

Table 2. Pairwise comparison of genetic differentiation among 6 geographic populations of black bears Ursus americanus from northeastern Mexico. Values are $R_{\mathrm{ST}}$ values based on microsatellite data. $\left({ }^{*}\right)$ significant difference from $0(\mathrm{p}<0.05)$. RMV: Real de Minas Viejas

\begin{tabular}{|lcccccc|}
\hline Population & $\begin{array}{c}\text { RMV/ } \\
\text { Villaldama }\end{array}$ & $\begin{array}{c}\text { Santa } \\
\text { Catarina }\end{array}$ & Picachos Linares & $\begin{array}{c}\text { Sierra } \\
\text { del Burro }\end{array}$ & $\begin{array}{c}\text { Sierra del } \\
\text { Carmen }\end{array}$ \\
\hline RMV/Villaldama & - & & & & & \\
Santa Catarina & 0.11 & - & & & & \\
Picachos & 0.28 & 0.16 & - & & & \\
Linares & 0.37 & 0.21 & 0.07 & - & & - \\
Sierra del Burro & 0.39 & 0.26 & 0.26 & 0.18 & - & \\
Sierra del Carmen & 0.33 & 0.31 & 0.32 & $0.41^{*}$ & 0.02 & - \\
\hline
\end{tabular}

Table 3. Proportion of genetic variation for nuclear microsatellite loci estimated by analysis of molecular variance $\left(\mathrm{AMOVA}_{i} \phi_{\mathrm{ST}}\right)$. The highest percentage of variation was found within populations and between individuals within populations. Significant values of genetic structure $\left(\phi_{\mathrm{ST}}\right)$ and significant inbreeding coefficients ( $\phi_{\mathrm{IS}}$ and $\left.\phi_{\mathrm{IT}}\right)$ values were found within the complex

\begin{tabular}{|c|c|c|c|}
\hline \multirow{2}{*}{$\begin{array}{l}\text { Source of variation } \\
\text { Between populations }\end{array}$} & \multirow{2}{*}{$\begin{array}{c}\begin{array}{c}\text { Percentage } \\
\text { of variation }\end{array} \\
6.0\end{array}$} & \multicolumn{2}{|c|}{$F$ coefficients } \\
\hline & & $\phi_{\mathrm{ST}}$ & 0.315 \\
\hline Within populations & 12.2 & $\phi_{\mathrm{IS}}$ & 0.143 \\
\hline $\begin{array}{l}\text { Between individuals } \\
\text { within populations }\end{array}$ & 82.7 & $\phi_{\text {IT }}$ & 0.318 \\
\hline
\end{tabular}

laldama to a third genetic cluster. Most of the sampled black bears were assigned to their original sampled sites, but some individuals exhibited genotypes that may have originated outside of their sampled sites, suggesting some degree of movement or admixture (Fig. 2).

The BOTTLENECK analysis revealed that the allele frequency distribution of our black bear populations was normal (L-shaped) and there was no significant deviation in heterozygosity $(p>0.5)$ from mutation-drift equilibrium using the 2-tailed Wilcoxon signed-rank test under the TPM model and the SMM ( $p>0.05)$.

\section{DISCUSSION}

Black bears are typically solitary animals, with low densities in their distributional ranges (Hellgren et al. 2005). Individuals are distributed in a scattered fashion throughout their habitat, so that there may be large distances between them. Our samples from black bears in 6 different sites in northeastern Mexico are an adequate representative subsample with which to assess levels of genetic variability of black bears in the area. The patterns of genetic variability in the populations of northeastern Mexico followed those found in other genetic studies of black bears (Triant et al. 2004, Onorato et al. 2007, Costello et al. 2008, Pelletier et al. 2011). The overall mean levels of genetic diversity in our study were similar to those found in 

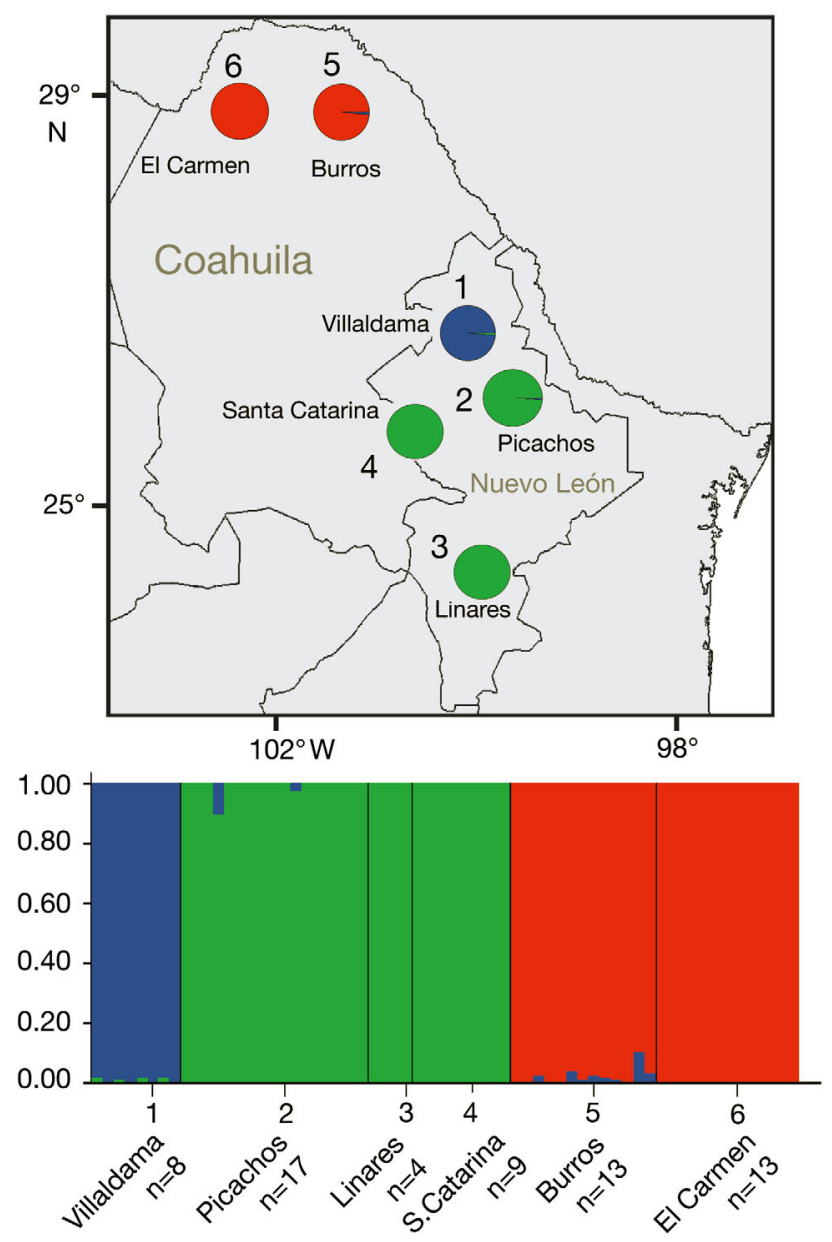

Fig. 2. Genetic structure of 3 clusters ( $K=3$, shown by different colors). Seventy percent of black bear Ursus americanus individuals were admixed, and most individuals from Sierra del Burro and Sierra del Carmen clustered together (shown in red). Numbers represent localities 1) Real de Minas Viejas/Villaldama, 2) Sierra de Picachos, 3) Linares, 4) Santa Catarina, 5) Sierra del Burro, and 6) Sierra del Carmen

Louisiana, USA (Triant et al. 2004), and lower than those found in western Texas and northern Mexico, where we share 2 identical localities (Sierra del Burro and Sierra del Carmen; Onorato et al. 2007). However, if we analyze these 2 localities separately from the rest of our study area, we also find that these areas have the highest genetic diversity and support the results proposed by Onorato et al. (2007). Our findings suggest a minimal continuous connectivity among those sites sampled where topographic barriers to gene flow seem to be weakest.

We found 2 localities (Real de Minas Viejas/Villaldama and Santa Catarina) out of HWE due to an observed heterozygosity deficiency. Both localities are close to the urban area of Monterrey, where black bears are frequently observed; however, we can find a stable black bear population in these localities, similar to other areas of its distribution (Beckmann \& Lackey 2008). Another possible explanation for the deficit of heterozygotes is the occurrence of null alleles (with low levels of ADO and the Villaldama locality out of HWE), which fail to amplify due to the mutational rate of the microsatellite. Null alleles have been reported in black bear populations (Paetkau \& Strobeck 1995, Triant et al. 2004), but expected frequencies of null alleles are relatively low and not significant enough to affect our estimates of genetic variability (Triant et al. 2004). Our MICROCHECKER results did not show the presence of null alleles in any of our 10 microsatellite loci, so this seems to be an unlikely explanation for the deficit of heterozygotes in the present study. Non-random mating caused by spatial clustering of related individuals could lead to inbreeding and homozygote excess in the population. Black bears are characterized by female philopatry and male-biased dispersal. In a previous study, relatedness and paternity of black bear populations of western Texas and northern Mexico indicated no potential inbreeding because of the continuous genetic supplementation facilitated by the high dispersal rates of adult males (Onorato et al. 2004).

Our results also show a significant degree of genetic differentiation between the populations in northeastern Coahuila (Sierra del Burro/Sierra del Carmen) and the rest of the localities. Studies in western Texas and northern Mexico showed the possibility of an episodic gene flow via desert corridors between Coahuila and the rest of the localities, resulting in moderate levels of genetic structuring (Onorato et al. 2007, Atwood et al. 2011). We found that Sierra del Carmen and Sierra del Burro are not genetically subdivided, and our results suggest that there are high levels of genetic connectivity between them. In contrast, the rest of the localities in the southeastern part of Nuevo León show null genetic structure, with some genetic connectivity. Southeastern localities in Nuevo Léon, however, are under the influence of more intense anthropogenic development (such as urban and industrial areas), impeding the panmictic movements of black bears. Previous results suggested a negative effect of anthropogenic influences such as road density and vehicular traffic on the population dynamics of black bears (Hostetler et al. 2009). Fixation indices are high and support the observed patterns of genetic structure which are similar to those found in 2 distinct populations 
of Louisiana, USA (Triant et al. 2004). Despite the fact that we used the same nuclear markers, each sampled area has unique geographic differences and species life history.

Several studies have assessed genetic variation in natural black bear populations throughout their distributional range (Triant et al. 2004, Onorato et al. 2007, Costello et al. 2008, Pelletier et al. 2011), and 4 have studied black bear populations of the southern USA and northern Mexico (Onorato et al. 2004, 2007, Costello et al. 2008, Varas-Nelson 2010). In general, populations from the southern USA exhibited much lower levels of genetic variation than populations found in northern Mexico (Onorato et al. 2007, Varas-Nelson 2010). Apparently, these high levels of genetic variation in northern Mexico are due to the high dispersal rate of populations coming from western Texas and not from populations from southern Arizona or New Mexico which are restricted to the 'sky island' habitat, with less mobility among individuals (VarasNelson 2010). Our findings resulted in 3 well-structured demes, one in western Coahuila that corresponds to the previously studied populations in Mexico (Onorato et al. 2007) and potentially has high genetic exchangeability with the populations of western Texas; and 2 populations in Nuevo León (one at Villaldama and another that includes Picacho, Linares, and Santa Catarina) with less microsatellite diversity and a low number of samples. Genetic differentiation between these 2 demes probably reflects the relationship of anthropogenic factors such as the urban areas, cultivated areas, and geographical barriers such as the Sierra Madre Oriental. The low levels of genetic diversity that we found in black bear populations from Nuevo León are not surprising given their patchy distribution and the fact that they do not have the same level of protection as the populations from western Coahuila (CONANP 2012).

In support of our predictions of restricted gene flow in Nuevo León populations, recent data in the urban area of Monterrey have shown that individual black bears can move long distances $(>20 \mathrm{~km})$ between the different mountain areas surrounding the city (CONANP 2010). Such movements crossing urban areas may be attributed to a lack of resources, such as food and water in their usual suitable habitat (Sierra Corona et al. 2005). Previous results suggest that landscape may play an important role in establishing the population structure of the black bear in its distributional range (Short Bull et al. 2011). Our population comparisons among localities of Nuevo
León suggested low levels of genetic differentiation, especially between localities which are separated by only a few kilometers, such as Real de Minas Viejas and Picachos, situated on the flanks of the mountains with no notable geographical barrier between them. On the other hand, populations from western Coahuila presented high pairwise differentiation compared to the localities of Nuevo León.

Our results have implications for the conservation and management of black bears in northeastern Mexico. Ursus americanus is arguably one of the most threatened mammals in northern Mexico. It is thought to be threatened primarily by habitat destruction and by anthropogenic activities. In Mexico, the black bear is listed as an endangered species (CONANP 2010) and is considered vulnerable throughout its distributional range (Ceballos et al. 2002). In the USA, field assessments in the south suggest that black bears are restricted to patchy habitats (Varas-Nelson 2010). This distribution suggests that populations may have a high probability of local extinction. $U$. americanus can be fairly common in western Coahuila, but the well-vegetated areas are generally restricted to the protected areas inhabited by the species. Additional research is needed to assess the extent to which individuals move between the relatively discrete patches of high-quality habitat in localities with more anthropogenic pressure, such as sites in Nuevo León.

Our data indicate that black bears form at least 3 distinct genetic clusters in northeastern Mexico. Furthermore, gene flow appears to be low among populations, with nearly all having different microsatellite frequencies. These populations may respond differently to environmental changes and should be considered distinct management units (Moritz 1994). Genetic evidence suggests that black bear populations of Nuevo León have lower levels of genetic variability and genetic connectivity compared with the populations of western Coahuila.

In conclusion, the use of microsatellite markers applied to non-invasive sampling was highly informative for understanding the patterns of genetic structure of black bear populations in northeastern Mexico. This work detected important levels of genetic differentiation among populations of western Coahuila and Nuevo León.

Acknowledgements. This work was supported by Proyecto SIP-20090474 and Proyecto Ciencia Básica CONACyT (156725). Fieldwork was conducted under the authority of a Special Use Permit from the Secretaría del Medio Ambiente y Recursos Naturales (SEMARNAT). We thank Hebert Nieto and Luis Juárez for assistance in the field. 


\section{LITERATURE CITED}

Aljanabi SM, Martínez I (1997) Universal and rapid saltextraction of high quality genomic DNA for PCR-based techniques. Nucleic Acids Res 25:4692-4693

Archie EA, Maldonado JE, Hollister-Smith JA, Poole JH, Moss CJ, Fleischer RC, Alberts SC (2008) Fine-scale population genetic structure in a fission-fusion society. Mol Ecol 17:2666-2679

> Atwood TC, Young KJ, Beckmann JP, Breck SW, Fike J, Rhodes OE Jr, Bristow KD (2011) Modelling connectivity of black bears in a desert sky island archipelago. Biol Conserv 144:2851-2862

Beckmann JP, Lackey CW (2008) Carnivores, urban landscapes, and longitudinal studies: a case history of black bears. Hum-Wildl Conflicts 2:168-174

Bergl RA, Vigilant L (2007) Genetic analysis reveals population structure and recent migration within the highly fragmented range of the Cross River gorilla (Gorilla gorilla diehli). Mol Ecol 16:501-516

Brookfield JFY (1996) A simple new method for estimating null allele frequency from heterozygote deficiency. Mol Ecol 5:453-455

Ceballos G, Arroyo-Cabrales J, Medellín RA (2002) The mammals of Mexico: composition, distribution, and conservation status. Occas Pap Mus Tex Tech Univ 218:1-27

CONANP (Comisión Nacional de Áreas Naturales Protegidas) (2010) Programa de acción para la conservación de la especie (PACE): oso negro americano, Ursus americanus. Instituto Nacional de Ecología, SEMARNAT, Mexico City

CONANP (2012) Programa de manejo del área protección de flora y fauna de Maderas del Cármen, México. Instituto Nacional de Ecología, SEMARNAT, Mexico City

> Corander J, Waldmann P, Sillanpää MJ (2003) Bayesian analysis of genetic differentiation between populations. Genetics 163:367-374

> Cornuet JM, Luikart G (1996) Description and power analysis of two tests for detecting recent population bottlenecks from allele frequency data. Genetics 144: 2001-2014

> Costello CM, Creel SR, Kalinowski ST, Vu NV, Quigley HB (2008) Sex-biased natal dispersal and inbreeding avoidance in American black bears as revealed by spatial genetic analyses. Mol Ecol 17:4713-4723

> Doan-Crider DL, Hellgren EC (1996) Population characteristics and winter ecology of black bears in Coahuila, Mexico. J Wildl Manag 60:398-407

Eggert LS, Maldonado JE, Fleischer RC (2005) Nucleic acid isolation from ecological samples-animal scat and other associated materials. Methods Enzymol 395:73-87

Evanno G, Regnaut S, Goudet J (2005) Detecting the number of clusters of individuals using the software STRUCTURE: a simulation study. Mol Ecol 14:2611-2620

> Excoffier L, Smouse P, Quattro JM (1992) Analysis of molecular variance inferred from metric distances among DNA haplotypes: application to human mitochondrial DNA restriction data. Genetics 131:479-491

Excoffier L, Laval G, Schneider S (2005) Arlequin ver. 3.0: an integrated software package for population genetics data analysis. Evol Bioinform Online 1:47-50

Friesen VL, González JA, Cruz-Delgado F (2006) Population genetic structure and conservation of the Galapagos petrel (Pterodroma phaeopygia). Conserv Genet 7: 105-115
Goudet J (2001) FSTAT, a program to estimate and test gene diversities and fixation indices (version 2.9.3). Available at www2.unil.ch/popgen/softwares/fstat.htm

Hájková P, Zemanová B, Bryja J, Hájek B, Roche K, Tkadlec E, Zima J (2006) Factors affecting success of PCR amplifications of microsatellite loci for otter faeces. Mol Ecol Notes 6:559-562

Hardy OJ, Charbonnel N, Fréville H, Huertz M (2003) Microsatellite allele sizes: a simple test to assess their significance on genetic differentiation. Genetics 163: 1467-1482

Heller R, Okello JBA, Siegismund H (2010) Can small wildlife conservancies maintain genetically stable populations of large mammals? Evidence for increased genetic drift in geographically restricted populations of Cape buffalo in East Africa. Mol Ecol 19:1324-1334

Hellgren EC, Onorato DP, Skiles JR (2005) Dynamics of a black bear population within a desert metapopulation. Biol Conserv 122:131-140

> Holsinger KE, Weir BS (2009) Genetics in geographically structured populations: defining, estimating and interpreting $F_{S T}$. Nat Rev Genet 10:639-650

> Hostetler JA, McCown JW, Garrison EP, Neils AM and others (2009) Demographic consequences of anthropogenic influences: Florida black bears in north-central Florida. Biol Conserv 142:2456-2463

Jiménez-Guzmán A, Zúñiga-Ramos MA (1991) Caracterización biológica de las Sierras Maderas del Carmen, Coahuila, México. An Inst Biol Univ Nac Auton Mex Ser Zool 62:373-382

Kalinowski ST (2005) HP-RARE 1.0: a computer program for performing rarefaction measures of allelic richness. Mol Ecol Notes 5:187-189

> Lampa S, Gruber B, Henle K, Hoehn M (2008) An optimisation approach to increase DNA amplification success of otter faeces. Conserv Genet 9:201-210

> Larivière S (2001) Ursus americanus. Mamm Species 647: 1-11

Lawson Handley LJ, Perrin N (2007) Advances in our understanding of mammalian sex-biased dispersal. Mol Ecol 16:1559-1578

LeCount AL, Yarchin JC (1990) Black bear habitat use in east central Arizona. Tech Rep 4. Arizona Game and Fish Department, Phoenix, AZ

> Luikart G, Cornuet JM (1998) Empirical evaluation of a test for identifying recently bottlenecked populations from allele frequency data. Conserv Biol 12:228-237

McDevitt AD, Oliver MK, Piertney SB, Szafranska PA, Konarzewski M, Zub K (2013) Individual variation in dispersal associated with phenotype influences finescale genetic structure in weasels. Conserv Genet 14: 499-509

> Meredith EP, Rodzen JA, Banks JD, Jones KC (2009) Characterization of 29 tetranucleotide microsatellite loci in black bear (Ursus americanus) for use in forensic and population applications. Conserv Genet 10:693-696

Miller AH (1955) The avifauna of Sierra del Carmen of Coahuila, Mexico. Condor 57:154-178

Moritz C (1994) Defining 'Evolutionarily Significant Units' for conservation. Trends Ecol Evol 9:373-375

> Muldavin EH (2002) Some floristic characteristics of the northern Chihuahuan desert: a search for its northern boundary. Taxon 51:453-462

Nei M (1987) Molecular evolutionary genetics. Columbia University Press, New York, NY 
Onorato DP, Hellgren EC, Van Den Bussche RA, Skiles JR Jr (2004) Paternity and relatedness of American black bears recolonizing a desert montane island. Can J Zool 82: $1201-1210$

Onorato DP, Hellgren EC, Van Den Bussche RA, DoanCrider DL, Skiles JR Jr (2007) Genetic structure of American black bears in the desert southwest of North America: conservation implications for recolonization. Conserv Genet 8:565-576

Paetkau D, Strobeck C (1995) The molecular basis and evolutionary history of a microsatellite null allele in bears. Mol Ecol 4:519-520

Pelletier A, Obbard ME, White BN, Doyle C, Kyle CJ (2011) Small-scale genetic structure of American black bears illustrates potential postglacial recolonization routes. J Mammal 92:629-644

> Piry S, Luikart G, Cornuet JM (1999) BOTTLENECK: a computer program for detecting recent reductions in the effective size using allele frequency data. J Hered 90: 502-503

Pritchard JK, Stephens M, Donnelly P (2000) Inference of population structure using multilocus genotype data. Genetics 155:945-959

Raymond M, Rousset F (1995) GENEPOP (version 1.2): population genetics software for exact tests and ecumenicism. J Hered 86:248-249

Rice WR (1989) Analyzing tables of statistical tests. Evolution 43:223-225

Short Bull RA, Cushman SA, Mace R, Chilton T and others (2011) Why replication is important in landscape genetics: American black bear in the Rocky Mountains. Mol Ecol 20:1092-1107

Sierra Corona R, Sáyago Vázquez IA, del Carmen Silva Hurtado M, López González CA (2005) Black bear abundance, habitat use, and food habits in the Sierra San Luis,

Editorial responsibility: Mike Bruford,

Cardiff, UK
Sonora, México. US Dept Agric For Serv Proc RMRS-P36:444-448

Small MP, Frye AE, Von Bargen JF, Young SF (2006) Genetic structure of chum salmon (Oncorhynchus keta) populations in the lower Columbia River: Are chum salmon in cascade tributaries remnant populations? Conserv Genet 7:65-78

Taberlet P, Griffin S, Goossens B, Questiau S and others (1996) Reliable genotyping of samples with very low DNA quantities using PCR. Nucleic Acids Res 24: 3189-3194

- Triant DA, Pace RM III, Stine M (2004) Abundance, genetic diversity and conservation of Louisiana black bears (Ursus americanus luteolus) as detected through noninvasive sampling. Conserv Genet 5:647-659

Valière N, Berthier P, Mouchiroud D, Pontier D (2002) GEMINI: a software for testing the effects of genotyping errors and multi-tubes approach for individual identification. Mol Ecol Notes 2:83-86

> Van Oosterhout C, Hutchinson WF, Wills DPM, Shipley P (2004) MICROCHECKER: software for identifying and correcting genotyping errors in microsatellite data. Mol Ecol Notes 4:535-538

Varas-Nelson AC (2010) Conservation genetics of black bears in Arizona and northern México. PhD thesis, University of Arizona, Tucson, AZ

- Waits LP, Luikart G, Taberlet P (2001) Estimating the probability of identity among genotypes in natural populations: cautions and guidelines. Mol Ecol 10:249-256

> Weir BS, Cockerham CC (1984) Estimating F-statistics for the analysis of population structure. Evolution 38: 1358-1370

Woods JG, Paetkau D, Lewis D, McLellan BN, Proctor M, Strobeck C (1999) Genetics tagging of free-ranging black and brown bears. Wildl Soc Bull 27:616-627

Submitted: September 3, 2013; Accepted: June 9, 2014

Proofs received from author(s): November 3, 2014 